\title{
PEROLD-SHARPE REBALANCING STRATEGIES IN PRACTICE
}

\author{
Valentyn KHOKHLOV ${ }^{1}$ \\ Global Spirits, Ukraine
}

\begin{abstract}
The purpose of this paper is to investigate the different strategies for portfolio rebalanc-ing (buy-and-hold, constant weights, and constant-proportion portfolio insurance (CPPI) suggested by Perold and Sharpe in a reallife environment using the actual market data and considering trans-action costs. Methodology. Exchange-traded funds were used to represent asset classes, and actual market prices in 2007-2015 for the ETFs used to conduct the research. The Monte-Carlo simulations were used to generate 400 portfolios over 3 different time horizons in order to get a representative sample. Two actual fee structures were used from the leading U.S. brokerage firms. Results of the portfolio dynamics research show outperformance of CPPI over other strategies on holding periods over 36 months, and on shorter time horizons CPPI and constant weights strategies clearly dominate over buyand-hold strategy. Contrary to the previous conclusions by Perold and Sharpe, there was no definite link between the stock market dynamics or volatility and the preferred strategy. We also see that after a bull market period the CPPI portfolio allocation shifts to $100 \%$ equity. The portfolio turnover is typically higher and much more dispersed for CPPI strategy than for constant weights strategy. We also found a strong negative correlation between the CPPI portfolio turnover and the initial equity allocation, whereas for constant weights strategy the turnover is higher at $50 \%$ allocation to both stocks and bonds. Practical implications. The strategy choice is shown to be more a matter of the holding period; CPPI seems the best choice over longer periods. Contrary to the widespread perception, our research shows that brokerage fees has not had a material influence on the simulated portfolio performance and, thus, should not be a factor for choosing a strategy. Originality/value. Unlike previous studies in this area that focused on analytical derivation based on sample statistics, we used the Monte-Carlo simulation on the actual asset prices and brokerage fees structures. The results of our research are much closer to the actual portfolio dynamics seen in practice. We also address issues like portfolio turnover and transaction costs that are often over-looked by academic researchers.
\end{abstract}

Key words: portfolio management, rebalancing, portfolio turnover, transaction costs, Monte Carlo simulation.

JEL Classification: G11, G17

\section{Introduction}

Portfolio rebalancing is an area of a great practical significance, since any portfolio manager should decide how to cope with deviations of actual asset weights from their targets. However, the academics generally paid little attention to this topic. Perold and Sharpe in their seminal paper (Perold, 1988) formally introduced and analyzed three rebalancing strategies - buy-and-hold (BH), constant mix or constant weights $(\mathrm{CW})$ and constant-proportion portfolio insurance (CPPI). The two former strategies had always been used by practitioners with a constant tradeoff between keeping the current weights up to their target values and saving on transaction fees. The third strategy, CPPI, was much more uncommon in practice despite its mechanics was investigated in much great details by Black and Perold (Black, 1992).

It was concluded by Perold and Sharpe that CW strategies are better on volatile, trendless market, whereas
CPPI in the best on a trendy market. Other researchers, e.g. (Blanchett, 2011), argue that BH strategy is not dead if both transaction costs and tax implications are considered. Yet another aspect of the rebalancing was investigated in (Leibowitz, 2001) that shows that a constant risk tolerance implies changing the asset allocation itself instead of keeping the constant $60 / 40 \mathrm{mix}$, which was used as a benchmark asset allocation by previous researchers.

The purpose of this paper is to investigate practical issues of portfolio rebalancing. Research objectives include checking Perold-Sharpe strategies on different holding periods and during different stock market conditions, using MonteCarlo simulations to check their behaviour on different time periods, analyze the portfolio turnover and the effect of transaction costs. We use both actual funds data and MonteCarlo simulation to generate portfolios. As Perold-Sharpe, we focus on the broad stocks-bonds portfolios, so we use ETF funds that represent those asset classes broadly and do not consider portfolios of individual securities.

\footnotetext{
Corresponding author:

${ }^{1}$ International Marketing Manager, Global Spirits.

Email:val.khokhlov@gmail.com
} 
The paper starts with the analysis of $\mathrm{BH}, \mathrm{CW}$, and CPPI strategies for a traditional 60/40 stocks-bonds portfolio in 2007-2015, then the results are generalized using three samples of 400 Monte-Carlo simulated portfolios with three different holding periods ( 5 years, 3 years, 18 months). After that the portfolio turnover and the effect of transaction costs are considered both for different transaction costs models and different initial portfolio allocations.

\section{Performance over the entire holding period}

Perold and Sharpe is their research used a simple portfolio consisting of two assets, the risky asset and the risk-free asset. Their approach is modelled in this research using investable assets and actual prices. SPY exchangetraded fund is used as a proxy to the risky asset (stocks). Finding a suitable proxy for the risk-free asset is more challenging, since investing directly into the Treasuries is not always an alternative for small investors. That's why two ETFs may be considered - BIL, which is a straightforward alternative for the bills considered by Perold and Sharpe but is virtually a zero-return zero-volatility asset, and TLT, which provides a more interesting risk-return profile while keeping credit risk at zero and having no correlation with stocks. The latter has been chosen as a more viable alternative. Given the availability of price data, the longest time horizon accessible for our analysis are 102 months from July 2007 to December 2015.

The three portfolios, representing $\mathrm{BH}, \mathrm{CW}$ and CPPI strategies respectively, were created on June 30, 2007 by investing \$1,000,000 with the initial asset allocation 60\% stocks, 40\% bonds (technically, 3988 SPY shares and 4697 TLT shares were bought). The $\mathrm{BH}$ portfolio was never changed after that. The CW portfolio was rebalanced at the beginning of each month by keeping the constant weights at $60 \%$ and $40 \%$ respectively. The CPPI portfolio was rebalanced at the beginning of each month using the Perold-Sharpe formula for the amount invested in stocks with the floor lev-el of $\$ 700,000$ and $\mathrm{m}=2$ :
Dollars in Stocks $=\mathrm{m}$ (Assets - Floor $)$

The dynamics of the actual asset allocation for $\mathrm{BH}, \mathrm{CW}$ and CPPI portfolios is shown on Figure 1. Surprisingly the $\mathrm{BH}$ portfolio reverted to almost $60 / 40$ allocation in $2014-$ 2015 , so at the end of the holding period its structure was very similar to the $\mathrm{CW}$ portfolio. The common sense may say that it did not make much sense to spend money on monthly rebalancing just to end up with the same asset mix. However, if the actual performance results are checked (see Table 1 ), the annualized return of CW strategy is $0.8 \%$ higher and that is more than enough (as will be discussed below) to compensate for the additional costs incurred. The asset mix for CPPI strategy is quite different - while it stayed pretty similar to the $\mathrm{BH}$ portfolio during turbulent times of the 2008-2009 crisis, on the rebounding market the CPPI portfolio structure quickly shifted to $100 \%$ equity allocation, and its annualized return over the entire holding period turned out to be significantly higher than for two other strategies.

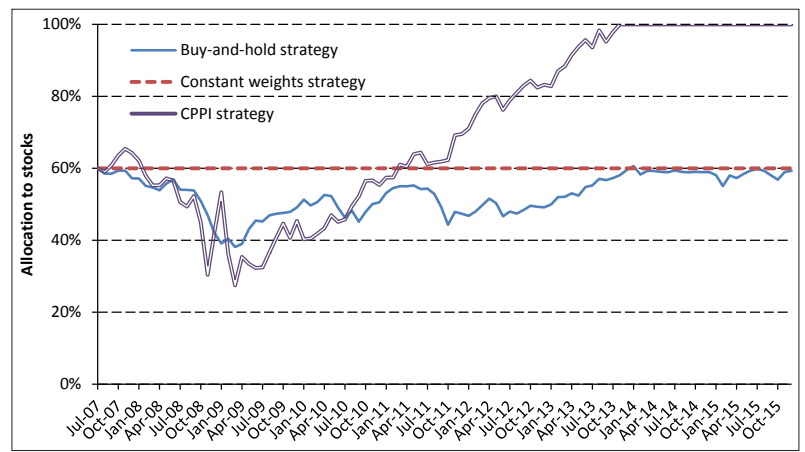

Fig. 1. Dymanics of the actual asset allocation for $\mathrm{BH}, \mathrm{CW}$ and CPPI strategies

As readers may note from Table $1, \mathrm{BH}$ strategy dominates (i.e. delivers the highest current return) during 37 months between July 2007 and December 2015, CW strategy during 22 months, whereas CPPI strategy dominates during 43 months. Another metrics of practical use would be the

Table 1

Performance and sample statistics of BH, CW and CPPI strategies in 2007-2015

\begin{tabular}{|c|c|c|c|}
\hline & Buy-and-hold & Constant weights & CPPI \\
\hline Total return, annualized & $3.86 \%$ & $4.63 \%$ & $6.16 \%$ \\
\hline Standard deviation, annualized & $9.18 \%$ & $9.56 \%$ & $10.43 \%$ \\
\hline \multicolumn{4}{|l|}{ Number of months with the highest } \\
\hline - return for the current month & 37 & 22 & 43 \\
\hline - cumulative return up to this month & 13 & 5 & 84 \\
\hline Average monthly return & $0.35 \%$ & $0.42 \%$ & $0.54 \%$ \\
\hline Standard deviation of monthly returns & $2.65 \%$ & $2.76 \%$ & $3.01 \%$ \\
\hline Skewness & -1.2341 & -1.3301 & -0.5174 \\
\hline Excess kurtosis & 4.3774 & 3.8289 & 1.9440 \\
\hline Minimal monthly return & $-11.17 \%$ & $-10.78 \%$ & $-10.48 \%$ \\
\hline $5 \%$ percentile of monthly returns & $-3.95 \%$ & $-3.98 \%$ & $-3.97 \%$ \\
\hline Median monthly return & $0.66 \%$ & $0.62 \%$ & $0.77 \%$ \\
\hline $95 \%$ percentile of monthly returns & $3.51 \%$ & $4.14 \%$ & $4.80 \%$ \\
\hline Maximal monthly return & $7.55 \%$ & $6.04 \%$ & $8.51 \%$ \\
\hline
\end{tabular}


number of months a particular strategy delivered the highest cumulative return, i.e. the value of the portfolio at the end of the corresponding month was the greatest. The picture is quite different here. CPPI strategy is the clear favourite outperforming $\mathrm{BH}$ and $\mathrm{CW}$ strategies in 84 of 102 months. $\mathrm{BH}$ strategy was the best during 13 early months, mostly in early 2008, and CW provided the highest value of the portfolio only during 5 months. The dynamics of the total cumulative return for different strategies is plotted on Figure 2.

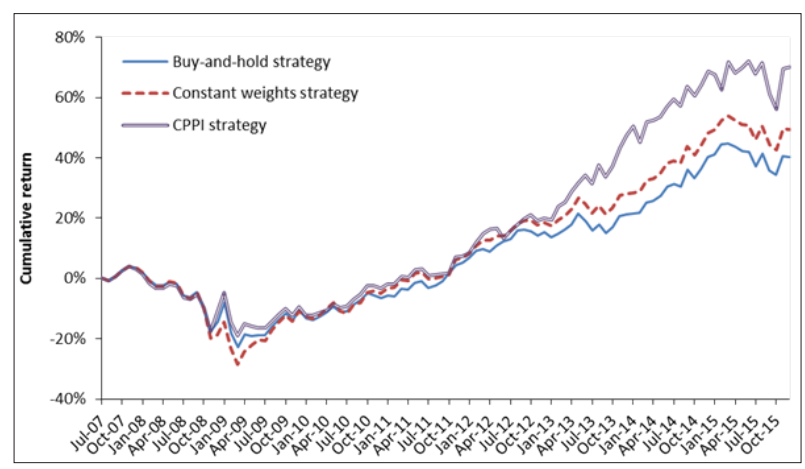

Fig. 2. Dynamics of the total cumulative return for $\mathrm{BH}, \mathrm{CW}$ and CPPI strategy

The sample statistics of 102 monthly returns for each portfolio are provided in Table 1 . While the average return for CPPI is much higher than for $\mathrm{CW}$ or $\mathrm{BH}$ (which is natural given its outperformance in terms of the total return), the dispersion of monthly returns as measured by the standard deviation is also higher for CPPI, however that difference is not huge. Hence in terms of the Sharpe ratio CPPI strategy is clearly preferential. While the mean return and its standard deviation steadily increase as we shift from $\mathrm{BH}$ to $\mathrm{CW}$ and from $\mathrm{CW}$ to CPPI, it's not the case for down-side risk. All three portfolios are comparable in terms of $5 \%$ percentile (which is a sample measure corresponding to VaR 5\%). It's also interesting to note that the median return is higher for $\mathrm{BH}$ than for $\mathrm{CW}$ strategy, contrary to the average return.

CPPI strategy clearly dominated on the upward trend in 2011-2015 and, surprisingly, during market slump in the second half on 2008. However, during the most part of 2009-2010, especially on the rebounding market, CW appeared to be the best strategy. According to the PeroldSharpe analysis, there should have been a correlation between the stock market volatility and the best strategy during that period. The current volatility (proxied by the monthly standard deviation of the daily SPY returns) was plotted on Figure 3 with the shaded bars indicating the strategy that worked best during the given month. However, it is not possible to conclude there is a correlation between the volatility and the best strategy, because during various periods of high volatility (October 2008, March 2009, and August 2011) different strategies provided the highest returns. Also, during the periods of low volatility there was no clear preference for any particular strategy, albeit CPPI may have been slightly more preferable.

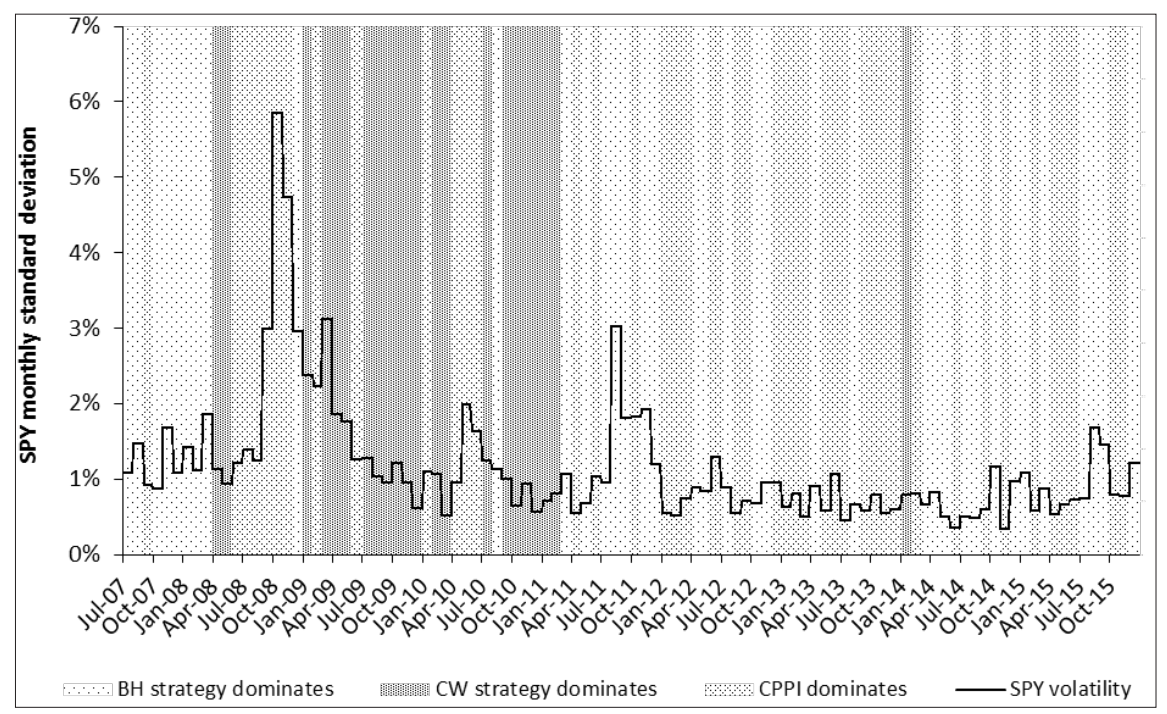

Fig. 3. Dominant strategy dependence on the stock market volatility

\section{Simulated portfolios over smaller holding periods}

After having considered three strategies over the entire holding period of 102 months, the Monte Carlo simulation was performed over smaller randomly selected holding periods ( 60 months, 36 months, and 18 months). Each simulation consisted of randomly choosing a starting date, investing $\$ 1,000,000$ in a $60 \%$ SPY $40 \%$ TLT mix and running three portfolios $(\mathrm{BH}, \mathrm{CW}$, and $\mathrm{CPPI})$ with monthly rebalancing for the selected holding period. 400 simulations were run for each holding period length.

The simulation with 60 months holding period (see Panel A in Table 2) shows clear outperformance of CPPI over other strategies. It delivers the best performance for 357 of 400 portfolios, whereas CW strategy dominates for 39 portfolios, most of which were started in 2007 and 
early 2008 , so they had a greater exposure to the financial crisis. Hence it can be concluded that CPPI strategy was dominant on the post-crisis growing market, however during the turbulent times of 2008-2009 CW strategy was better.

The results for the simulation with 36 months holding period (see Panel B in Table 2) differ from the ones discussed above immaterially for $\mathrm{BH}$ and $\mathrm{CW}$ strategies, but CPPI strategy generates lower returns. The amount of portfolios for which CPPI dominated is significantly lower than be-fore, and at 36 months holding period much more $\mathrm{CW}$ portfolios become dominant. When the holding period is reduced further to 18 months (see Panel C in Table 2), the returns for all three strategies become much more aligned. Whereas $\mathrm{BH}$ and $\mathrm{CW}$ average returns are slightly lower, there is a significant drop in the average return for CPPI strategy. While the numbers of dominant portfolios for each strategy stays about the same as for 36 months holding period, the $95 \%$ confidence intervals for all strategies have a substantial overlap. So, as the holding period shortens the distinction between the strategies blurs.

The total portfolio turnover, which is calculated as the total value of transactions executed for rebalancing divided by the initial portfolio value, is zero for $\mathrm{BH}$ but becomes quite significant for $\mathrm{CW}$ and CPPI (see Table 2). It's a common perception that $\mathrm{BH}$ strategy may turn out to be more desirable when after-fees returns are considered. However, when taking typical commission structures used by the major brokerage firms into account, it becomes apparent that the reduction in average return after fees is not significant. Two fee models were modelled - the volume-based model, which depends on the amount of shares traded, and the flat-fee model, which is based on a fixed fee per trade. The fees were calculated as follows:

- for the volume-based model: $\$ 0.005$ per each share traded, subject to a floor of $\$ 1$ per trade and to a cap of $0.5 \%$ of the total trade value;

- for the flat-fee model: $\$ 6.95$ per trade.

For our portfolio of $\$ 1,000,000$ the typical transaction fees were way below $\$ 1,000$ even for 5 years holding period. Therefore, the maximum decrease in total return for the entire holding period is less than $0.1 \%$, or less than $0.02 \%$ when annualized. In general, the volume-based model generates lower fees when there are many smaller transactions (in our case the monthly minimum commission is waived since the NAV of the portfolio is higher than $\$ 100,000$ ), whereas the flat-fee model favours a small number of large trades. However, for both fee models considered, as well as for any model that is reasonably competitive with those two, the amount of commissions is way too small to justify switching from a strategy chosen on before-fees basis.

\section{Effect of holding period length on turnover}

The total portfolio turnover is analyzed over various holding periods ranging from 12 to 60 months using 100 Monte-Carlo simulations. The starting date was

Table 2

Monte-Carlo simulation results for BH, CW and CPPI strategies over different holding periods

\begin{tabular}{|c|c|c|c|}
\hline Panel A. Holding period 60 months & Buy-and-hold & Constant weights & CPPI \\
\hline Average return before fees, annualized & $7.87 \%$ & $8.34 \%$ & $9.92 \%$ \\
\hline - standard error & $0.19 \%$ & $0.17 \%$ & $0.21 \%$ \\
\hline - $95 \%$ confidence interval & $7.50 \%-8.24 \%$ & $8.02 \%-8.66 \%$ & $9.51 \%-10.34 \%$ \\
\hline Portfolios where the strategy dominates & 4 & 39 & 357 \\
\hline Average portfolio turnover & $0 \%$ & $197 \%$ & $280 \%$ \\
\hline - fees, volume-based model & $<0.01 \%$ & $0.02 \%$ & $0.02 \%$ \\
\hline - fees, flat-fee model & $<0.01 \%$ & $0.08 \%$ & $0.07 \%$ \\
\hline Panel B. Holding period 36 months & Buy-and-hold & Constant weights & CPPI \\
\hline Average return before fees, annualized & $7.84 \%$ & $8.45 \%$ & $9.18 \%$ \\
\hline - standard error & $0.26 \%$ & $0.25 \%$ & $0.30 \%$ \\
\hline - 95\% confidence interval & $7.33 \%-8.36 \%$ & $7.95 \%-8.94 \%$ & $8.59 \%-9.77 \%$ \\
\hline Portfolios where the strategy dominates & 14 & 161 & 225 \\
\hline Average portfolio turnover & $0 \%$ & $114 \%$ & $201 \%$ \\
\hline - fees, volume-based model & $<0.01 \%$ & $0.01 \%$ & $0.02 \%$ \\
\hline - fees, flat-fee model & $<0.01 \%$ & $0.05 \%$ & $0.05 \%$ \\
\hline Panel C. Holding period 18 months & Buy-and-hold & Constant weights & CPPI \\
\hline Average return before fees, annualized & $7.35 \%$ & $7.48 \%$ & $8.17 \%$ \\
\hline - standard error & $0.46 \%$ & $0.46 \%$ & $0.45 \%$ \\
\hline - $95 \%$ confidence interval & $6.46 \%-8.24 \%$ & $6.58 \%-8.39 \%$ & $7.30 \%-9.05 \%$ \\
\hline Portfolios where the strategy dominates & 16 & 156 & 228 \\
\hline Average portfolio turnover & $0 \%$ & $54 \%$ & $102 \%$ \\
\hline - fees, volume-based model & $<0.01 \%$ & $0.01 \%$ & $0.01 \%$ \\
\hline - fees, flat-fee model & $<0.01 \%$ & $0.03 \%$ & $0.03 \%$ \\
\hline
\end{tabular}


randomly selected so that the holding period fits between July 1, 2017 and December 31, 2015. Of course, for $\mathrm{BH}$ strategy the turnover is zero. For CW and CPPI strategy a strong positive link between the holding period and the turnover is found (see Figure 4), however the dispersion of the turnover is much higher for CPPI. It can be explained by the fact that portfolios held during 2012-2015 are likely to shift to $100 \%$ equity

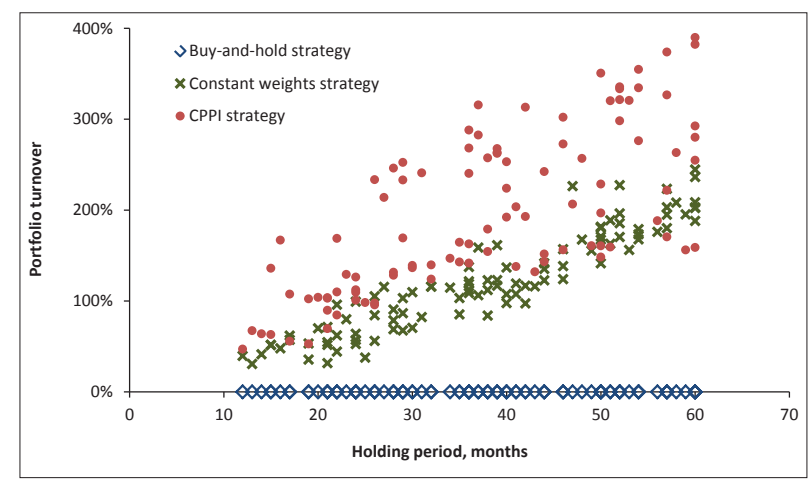

Fig. 4. Portfolio turnover dependence on the holding period length allocation under CPPI strategy, which decreased their rebalancing needs and turnover comparing to those held during 2007-2011. On the other hand, the turnover under CW strategy is much more consistent, because the target asset weights remain the same.

If the dependence of the total broker commission to the holding period length is considered, however, a different picture appears. The flat-fee model (see Panel $\mathrm{B}$ on Figure 5) generates linearly increasing fees for $\mathrm{CW}$ strategy and for most portfolios under CPPI strategy, because the number of trades is proportional to the number of rebalancing (i.e. the number of months the portfolio is being held). The only exception is CPPI portfolios that shift to $100 \%$ equity allocation, as they do not re-quire subsequent rebalancing (they are the dots below the diagonal line on Panel B). The volumebased model (see Panel A on Figure 5) leads to quite different results, the fees increase with the length of the holding period, however, at a much slower rate. The scatter plot depicting the amount of fees in this case is quite similar to the scatter plot for the turnover, because for the volume-based model fees are proportional to the amount of trades.

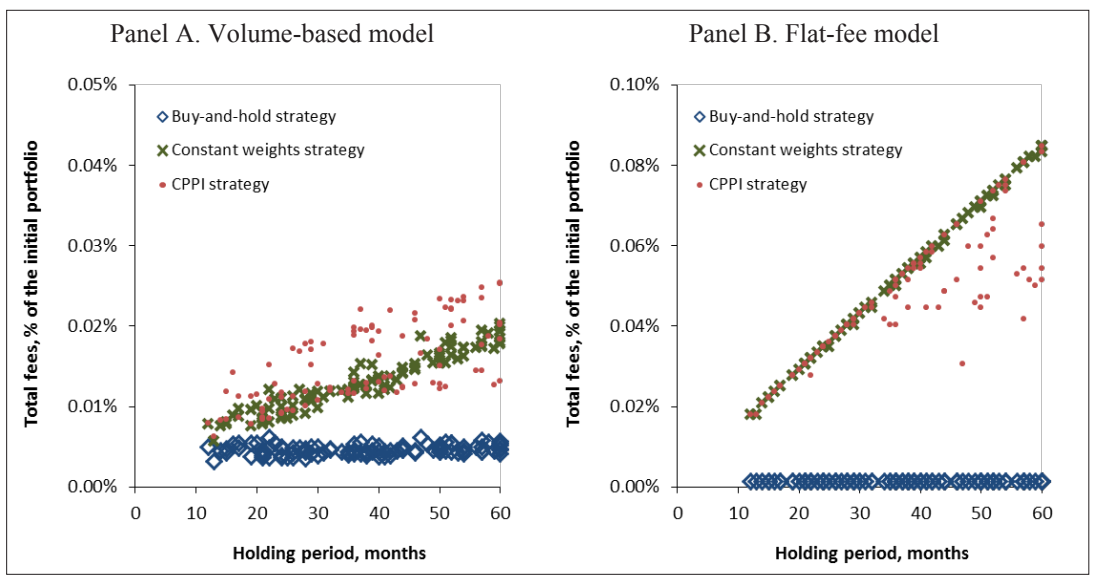

Fig. 5. Total brokerage commissions dependence on the holding period length

\section{Effect of initial asset allocation on turnover}

Finally, the total portfolio turnover for different initial portfolio composition is analyzed using 100 Monte-Carlo simulations on the total holding period of 60 month. The starting date is randomly selected so that the holding period fits between July 1 , 2017 and December 31, 2015, and the initial allocation to stocks is randomly chosen between $20 \%$ and $80 \%$. For the CPPI portfolio the floor level in formula (1) is adjusted accordingly.

$\mathrm{BH}$ strategy, again, has no turnover. The portfolio turnover for CW is much less dispersed than for CPPI, and the shapes are quite different for the strategies (see Figure 6). For CW strategy the turnover ranges from $100 \%$ to $250 \%$ and the shape is slightly bended upwards in the middle (i.e. turnover is higher for portfolios with the initial allocation to stocks $40 \%$ to

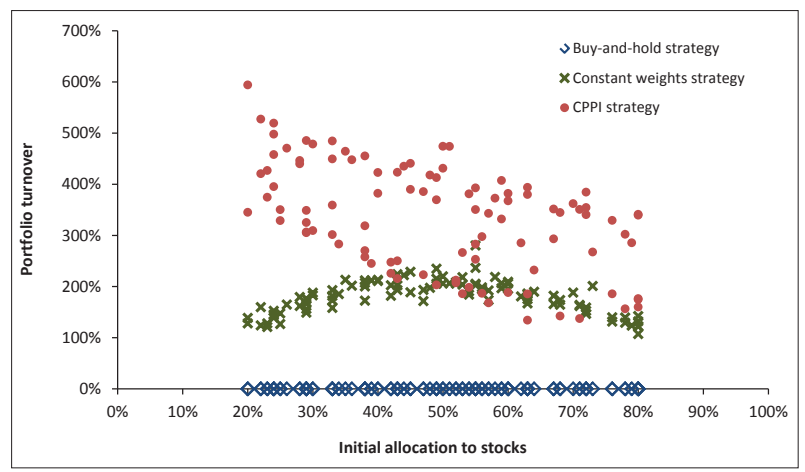

Fig. 6. Total portfolio turnover dependence on the initial portfolio allocation 
$60 \%$ than for those at the ends of the $20 \%-80 \%$ range). While the dispersion of the turnover for CPPI strategy is significantly greater, a strong negative correlation between the turnover and the initial allocation to stocks can be observed (i.e. the portfolios more exposed to equities have lower turnover). Probably, it is due to the fact that as a CPPI portfolio shifts to $100 \%$ equity allocation on the growing stock market less re-balancing is required.

The dependence between the total brokerage fees and the initial allocation to stocks (see Figure 7) is rather similar as the dependence between the commission and the holding period length. For the volume-based model the scatter plot is quite similar to scatter plot for the portfolio turnover, and the reason stays the same fees are proportional to the amount of shares traded. For the flat-fee model the total fee amount is the same irrespective of the portfolio allocation for CW strategy, but for CPPI strategy some portfolios result in a lower total commissions. Moreover, the higher is the initial allocation to stocks, the lower are the total fees - it supports our previous conclusion that some of the CPPI portfolios, which subsequently shift to $100 \%$ equities, require less rebalancing. Of course, some CPPI portfolios have never reached $100 \%$ allocation to stocks, and the amount of commissions stayed at the same level as for the CW portfolios.

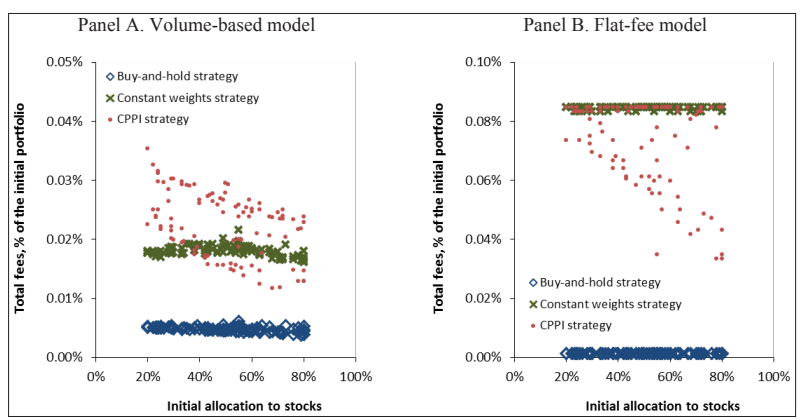

Fig. 7. Total brokerage commission dependence on the initial portfolio allocation

\section{Conclusions}

Three different portfolio rebalancing strategies buy-and-hold, constant weights and CPPI - have demonstrated different performance during the holding period considered in our research. Despite the fact that CW strategy performed better on a turbulent market in 2009-2010 and CPPI was certainly the best strategy on a growing market in 2011-2015, there is no evidence of definite correlation between the market volatility and the dominance of a particular rebalancing strategy. While there is some support for Perold and Sharpe conclusion that, in theory, CW should be superior in a market characterized by often reversals and CPPI should be better in a bull market, practice shows it is not always the case.

Another common perception that has not been confirmed in this research is the attractiveness of $\mathrm{BH}$ strategy given its zero transaction costs. On our sample $\$ 1,000,000$ portfolio the brokerage commissions were too small to justify changing the strategy because of the transaction costs and $\mathrm{BH}$ strategy was on average the least performing one. Most probably the same will hold true for any portfolio exceeding $\$ 100,000$ given the fact that brokers typically waive a minimal monthly payment on any portfolio larger than that. So, in our opinion, transaction fees should not be an es-sential consideration when choosing a rebalancing strategy over a sufficiently long time horizon.

Finally, the holding period length turns out to be a significant factor. On short time horizons (about 18 months) it does not really matter what strategy is being chosen, since no statistically sig-nificant difference in the mean returns has been found. However, as the portfolio is being held for a longer period the difference between strategies becomes more significant - CPPI outperforms CW and CW outperforms $\mathrm{BH}$. When the holding period is longer than 36 months, there is a $95 \%$ proba-bility that CPPI will outperform other strategies. Therefore $\mathrm{BH}$ strategy makes little sense for any investor over long time horizons, and unless there are specific reasons to keep asset weights constant and opt for CW strategy, CPPI strategy would be the best choice.

\section{References}

Black, F., Perold, A.F. (1992). Theory of constant proportion portfolio insurance. The Jour-nal of Economics, Dynamics and Control, Volume 16, Issue 3-4, p. 403-426.

Blanchett, D.M. (2011). Is Buy and Hold Dead? Exploring the Costs of Tactical Realloca-tion. Journal of Financial Planning, Volume 24, Issue 2, p. 54-61.

Leibowitz, M.L., Bova, A. (2011). Policy Portfolios and Rebalancing Behavior. Journal of Portfolio Management, Volume 37, Issue 2, p. 60-71.

Perold, A.F., Sharpe, W.F. (1988). Dynamic Strategies for Asset Allocation, Financial Ana-lyst Journal, Volume 44, Issue 1, p. 16-27. 


\section{Валентин ХОХЛОВ}

\section{СТРАТЕГИИ ПЕРЕБАЛАНСИРОВКИ РЕROLD-SHARРЕ НА ПРАКТИКЕ}

Аннотация. Целью статьи является исследование различных стратегий перебалансировки портфеля (buy-and-hold, постоянные веса и постоянная пропорция страхования портфеля (CPPI), предложенных Perold и Sharpe, в реалистичной обстановке с использованием рыночных цен и принимая во внимание транзакционные издержки. Методика. Для представления классов активов использованы биржевые фонды, по ним взяты реальные рыночные цены за 2007-2015 года. С помощью метода Монте-Карло сгенерированы по 400 портфелей на 3 разных горизонтах инвестирования, чтобы создать репрезентативную выборку. Две реальные структуры брокерских комиссий взяты исходя из комиссионной структуры крупных брокеров на рынке. Результаты исследования динамики портфелей показывают предпочтительность СРPI над другими стратегиями на горизонтах инвестирования от 36 месяцев, тогда как на более коротких горизонтах СРPI и стратегия постоянных весов является более предпочтительными, нежели стратегия buy-and-hold. Boпреки выводам Perold и Sharpe, не было обнаружено связи между ценовой динамикой или волатильностью рынков и предпочтением той или иной стратегии. Было замечено, что после периода «бычьего» рынка аллокация CPPI портфеля имеет тенденцию к сдвигу в 100\% акции. Оборот активов в портфеле является более быстрым и менее стабильным для стратегии CPPI по сравнению со стратегией постоянных весов. Мы также обнаружили сильную негативную корреляцию между оборотом CPPI портфеля и первоначальной аллокацией в акции, в то время как для стратегии постоянных весов наибольший оборот происходит при аллокации в акции и в облигации по 50\%. Практическое значение. Показано, что выбор стратегии зависит в первую очередь от горизонта инвестирования, на длинных горизонтах предпочтительной кажется стратегия CPPI. Вопреки распространенному мнению, наше исследование показывает, что брокерские комиссии не оказывали существенного влияния на результаты сгенерированных портфелей, поэтому они не должны быть определяющим фактором при выборе стратегии. Значение/оригинальность. В отличие от предыдущих исследований в этой области, которые фокусировались на аналитическом выводе и основывались на выборочных статистиках, мы использовали метод Монте-Карло на реальных ценовых данных и структуре брокерских комиссий. Результаты нашего исследования гораздо лучше характеризуют динамику портфелей на практике. Мы также затронули такие вопросы, как оборот портфеля и транзакционные издержки, которые зачастую упускают из виду академические исследователи. 